\title{
Under the dynamic environment of normal diagnosis and treatment in the bronchoscope room, the study of the removal efficiency of the new air purifier on microbial aerosols
}

\section{Lijuan Wu}

The Second Hospital of Hebei Medical University

XIXIN YAN ( $\nabla$ xi_xin_yan@126.com )

The Second Hospital of Hebei Medical University https://orcid.org/0000-0003-4014-6226

\section{Research}

Keywords: SARS-CoV-2 epidemic, Microbial aerosol, Bronchoscope room, Indoor environment, Dynamic diagnosis and treatment environment, New air purifier, Steady-state replacement flow, Fresh air system.

Posted Date: August 25th, 2021

DOI: https://doi.org/10.21203/rs.3.rs-812319/v1

License: (9) This work is licensed under a Creative Commons Attribution 4.0 International License.

Read Full License 


\section{Abstract \\ Background}

The SARS-CoV-2 can spread through droplets, aerosols, etc. In the case of a severe outbreak of the SARSCoV-2, the use of new air purifiers in work and living places has a certain effect on reducing the spread of the SARS-CoV-2. There are abundant microbial aerosols in the indoor medical environment. The innovation of this experiment lies in the use of long-term, large-volume sampling methods under the multi-factor dynamic conditions of normal diagnosis and treatment in the bronchoscope room, and the use of two microbial detection methods at the same time to study the removal efficiency of the new air purifier on microbial aerosols; The innovation of the new air purifier lies in outdoor fresh air and steadystate displacement flow technology.

\section{Methods}

In this experiment, the test group and the control group were set up. Gelatin filtration membrane and PTFE filtration membrane were used to sample the microbial aerosols in the bronchoscope room. Long time (39.5h) and large sampling volume (70590L) was used. A total of 16 days of pure working time sampling was carried out for a period of 1 month. The collected specimens were tested by two methods: nextgeneration sequencing (mNGS) and microbial culture identification. The researcher retrieved and recorded the microbiological test results of related patients, and compared them with the results of this experiment.

\section{Results}

The result of next-generation sequencing (mNGS): The total purification efficiency was $88.0 \%$. Microbial culture counting and identification results: the total purification efficiency is $87.5 \%$. The results are statistically significant. There is a certain correlation between the experimental results and the clinical microbiological test results of patients.

\section{Conclusions}

1. The new type of air purifier has a good effect on the removal of microbial aerosols in the bronchoscope room; 2. A variety of microorganisms involved in the experiment can be transmitted through aerosols.

\section{Discussion}

The new air purifier has a total removal efficiency of more than $85 \%$ of microorganisms under the dynamic environment of the hospital's normal diagnosis and treatment, and the purification efficiency of 
a single microorganism ranges $50 \%-100 \%$. Such removal efficiency may have a positive effect for the control of the SARS-CoV-2 epidemic.

\section{Highlights}

The innovation of this experiment lies in the use of long-term, large-volume sampling methods under the multi-factor dynamic conditions of normal diagnosis and treatment in the bronchoscope room, and the use of two microbial detection methods at the same time to study the removal efficiency of the new air purifier on microbial aerosols; The innovation of the new air purifier lies in outdoor fresh air and steadystate displacement flow technology.

\section{Background}

A large number of liquid particles are produced in human production and life, and the particle size of this part of the liquid particles is mostly between $0.001 \mu \mathrm{m}$ and $100 \mu \mathrm{m}$. Generally, the particle size: $5 \mu \mathrm{m}$ is the dividing line. The particles larger than $5 \mu \mathrm{m}$ are droplets, and the particles smaller than $5 \mu \mathrm{m}$ are aerosols ${ }^{[1]}$. Particles containing microorganisms are called microbial aerosols. The microbial aerosols collected in this experiment are a kind of small and medium particles. In recent years, the SARS-CoV-2 raging around the world can be spread through droplets, aerosols, etc ${ }^{[2]}$. The droplet is affected by gravity and has a short diffusion distance. It is a kind of short-distance transmission between people, and aerosols can remain suspended for a long time ${ }^{[3]}$, so microbial aerosols are an important cause of the transmission of indoor infectious diseases.

Because of the higher risk of medical staff being exposed to indoor microbial aerosols ${ }^{[4-5]}$. The risk ratio for health care workers to acquire viral or bacterial infections is $2.5^{[6]}$. The staff in the endoscopy room are at increased risk of contracting the SARS-CoV-2 ${ }^{[7]}$. Humans have long discovered that many microorganisms can be transmitted by droplets, but aerosol transmission is still unclear. Indoor microbial aerosol has an important impact on the the spread of established infectious pathogens such as the known SARS-CoV-2 ${ }^{[8]}$, Mycobacterium tuberculosis, measles virus, varicella-zoster virus ${ }^{\left[{ }^{[0}\right.}{ }^{10]}$, hand-footmouth disease virus ${ }^{[11]}$, Ebola virus and Middle East Respiratory Syndrome virus ${ }^{[12]}$. In addition, indoor microbial aerosols are important in different medical places such as operating room ${ }^{[13]}$, intensive care room $^{[2,14]}$, nasopharyngeal swab collection place ${ }^{[15]}$, endoscopy room ${ }^{[16]}$, Stomatology ${ }^{[20]}$, Otorhinolaryngology ${ }^{[17]}$, Gastroenterology ${ }^{[18]}$ and Ophthalmology ${ }^{[19]}$, etc. Microbial aerosols also have an important impact on medical staff and patients. The control of indoor microbial aerosols can also reduce the hospital infection rate of patients. The location of the sampling point designed in this experiment decides that the sampling membranes can only collect aerosols without droplets. Therefore, the experimental results can also confirm that the relevant microorganisms are transmitted through aerosols.

Some studies ${ }^{[21-22]}$ directly take samples from the filters of air conditioners or purifiers for microbiological testing, which indirectly confirms the purifying effect of the filter. However, the 
microorganisms on the filter will multiply, die or decompose, so the method above cannot directly reflect the microbial aerosols. Some scholars ${ }^{[23-27]}$ have confirmed that air purifiers can effectively reduce the concentration of allergens in indoor air, thereby improving the clinical manifestations of patients with allergic rhinitis, and significantly reducing the drug needs. Some scholars ${ }^{[28]}$ have proved that the air purifier has the effect of reducing the total colony number of the culture medium through the method of air sampling and fungus culture in the medium, but it has not been tested for bacterial species, and the purification of each microorganism cannot be seen directly. Some scholars ${ }^{[29-30]}$ use aerosol generators to artificially make certain virus and bacterial solutions into aerosols. Under the ideal conditions of a closed experimental chamber, they have confirmed that air purifiers have a certain purification effect on aerosols of specific types of microorganisms. It can intuitively reflect the purification effect, but it is not an evaluation of the purification effect on the microorganisms that actually exist under the dynamic environmental conditions of the normal diagnosis and treatment of the hospital. In animal experiments, some scholars ${ }^{[31]}$ have proved that air purifiers are effective in reducing the pathogenicity of certain viruses to animals by detecting the infection rate of animals to certain viruses, but they cannot directly reflect the purification of air purifiers on microbial aerosols.

The new type of air purifier used in this experiment is Aoxiang® Steady-State Displacement Flow Clean and Disinfection System, and the purification factor is steady-state displacement flow field and highefficiency air filtration technology. The new air purifier uses an energy-saving and efficient air cleaning technology: steady-state displacement flow technology. In the indoor environment between the air outlet and the air inlet, a "vector flow" one-way and propelling airflow is established, so that the particulate matter is removed with the minimum amount of diffusion. This technology can establish a push-type displacement flow field to form an air isolation barrier in the controlled area. It is a kind of purely physical epidemic prevention technology and may play a positive role in the prevention and control of epidemics in public places, including the medical environment.

\section{Materials And Methods}

This experiment is used in the dynamic environment of clinical practical work to actually investigate the purification effect of air purifiers on indoor microbial aerosols. In order to solve the multi-factor problems of uncertain number of patients, uncertain types of diseases, uncertain time of treatment, uncertain species of the collected microorganism, sufficient air collection to reach the lower limit of the detection method, and comparison of the purification efficiency of a single microorganism, the researchers used a long time (39.5h), large sampling capacity $(70590 \mathrm{~L})$ method. The collection time of the similar research ranges from $15 \mathrm{~min}-2 \mathrm{~h}$, and the collection volume ranges $50-2000 \mathrm{~L}^{[32-36]}$. In this experiment, a total of 16 days of pure working time sampling was carried out for a period of 1 month. The amount of air collected is large enough to represent the average purification efficiency of the microbial aerosol in the bronchoscope room, which is more statistically significant.

\subsection{Experimental equipment and experimental materials}


New air purifier (China Aoxiang), Circulating water vacuum pump (China Lichen), 37mm filter membrane sampling clip (USA SKC), Gelatin filter membrane (Germany Sartorius), PTFE filter membrane (China Chuangwei)

\subsubsection{The new type of air purifier.}

The new type of air purifier used in this experiment is Aoxiang® Steady-State Displacement Flow Clean and Disinfection System: Model AXY1, the batch number is 20201120004, and the purification factor is steady-state displacement flow field and high-efficiency air filtration technology.

\subsubsection{The filters:}

The gelatin filter membrane used in this experiment has a positive effect on maintaining microbial activity and has been widely used in air microbial sampling.

\subsection{Experimental conditions:}

Temperature ranges $23-26^{\circ} \mathrm{C}$, humidity ranges $40-65 \%$; the experimental conditions of the unpurified group and the purified group are the same.

\subsection{Distribution map:}

Schematic diagram of the distribution of sampling points in the bronchoscope room and related instructions

The plane position of the sampling point is shown in Figure-1. The five sampling points are located at 1/A, 2/B, 3/C, 4/D, 5/E shown in Fig. 1; The vertical height of the sampling point is $1.5 \mathrm{~m}$; The distance from the sampling points to the patients is $2.5-3 \mathrm{~m}$; Volume of bronchoscope room: $5 \star 6 \star 3 \mathrm{~m}=90 \mathrm{~m}^{3}$, Daily cases of operation: 0-20 cases/day; Total working time: 8-12h/d; Conventional disinfection measures: ultraviolet radiation and regular spraying of disinfectant during non-working hours.

\subsection{The main disease spectrum of patients in the bronchoscopy room during the experiment:}

Pneumonia; Bronchial lung cancer; Airway stenosis; Tuberculosis trachea; Bronchial tuberculosis; Aarcoidosis; Pleural cancer; Bronchitis; Tracheomalacia; Mediastinal lymphadenopathy; Tracheal mediastinal fistula; Tracheal fistula; Bronchial asthma; Allergic bronchopulmonary aspergillosis; Bronchial obsolete hemorrhage; Tracheal scar formation; Bronchial mucosal inflammation; Bronchial mucosal carbon-like deposition; Alveolar proteinosis; Organizing pneumonia; Pulmonary aspergillosis; Mediastinal lymph nodes Enlargement; Extrabronchial pressure stenosis; Bronchial foreign body; Esophageal cancer; Ossifying tracheobronchial disease; Bronchial granulation hyperplasia; Bronchial phlegm thrombus; T-cell lymphoma; Glottic polyp. 


\subsection{The level of treatment carried out in the bronchoscopy room:}

Bronchoalveolar lavage; Sputum suction; Electric snare therapy; Low-temperature plasma radiofrequency ablation; T tube placement; EBUS-TBNA; TBNA needle aspiration biopsy; Electric resection; Biopsy Forceps removal; Bronchial mucosal biopsy; Biopsy forceps removal treatment; Cryotherapy; Brushing; metal stent implantation; Tracheal cavity injection; Electronic bronchoscopy cryosurgery; Bronchial thermoplasty; Balloon Dilation therapy; Laser ablation; cryoablation; APC therapy; Net basket cleaning foreign body surgery; Rigid bronchoscopy; Virtual navigation.

\subsection{Sampling process:}

Half an hour after the patient enters the bronchoscope room in the working time, the researcher starts sampling. Use 1, 2, 3, 4, and 5 sampling membranes to sample the unpurified group for 1 hour, then turn on the purifier for 40 minutes of sampling. Keep the purifier open after 40 minutes, and use the A, B, C, D, and $E$ sampling membranes to sample the purified group for 1 hour. Sampling is carried out during normal working hours, and each membrane samples a total of $39.5 \mathrm{~h}$.

\subsection{Detection}

The second-generation sequencing (mNGS) test used in this experiment is undertaken by the Ice Source Medical Laboratory. It can detect 560 common clinical microorganisms including bacteria, fungi, viruses, most of which are bacteria and Fungus. The microbial culture and identification used in this experiment is undertaken by the Laboratory Department of the Second Hospital of Hebei Medical University. They are commonly used methods in clinical practice and have real reliability.

(1) Dissolve the sampling membranes of No. 1, 3, 4, and 5 after sampling in $4 \mathrm{ml}$ of sample storage solution dedicated to $\mathrm{mNGS}$, and place the dissolving mixture in a $37^{\circ} \mathrm{C}$ water bath for 7 minutes, and mark as the unpurified group. Dissolve the sampling membranes A, C, D, and E after sampling in $4 \mathrm{ml}$ of the second-generation sequencing (mNGS) special specimen storage solution, place them in a $37^{\circ} \mathrm{C}$ water bath for 7 minutes, and mark them as the purified group. The sample solution obtained in this step is tested by second-generation sequencing (mNGS).

(2) Dissolve the No. 2 sampling membrane in $2 \mathrm{ml}$ of normal saline, place it in a $37^{\circ} \mathrm{C}$ water bath for 7 minutes, and mark it as the unpurified group. Dissolve the B sampling membrane in $2 \mathrm{ml}$ of normal saline, place it in a $37^{\circ} \mathrm{C}$ water bath for 7 minutes, and mark it as the purified group. Extract $1 \mathrm{~mL}$ of each specimen, and inoculate it on Agar medium and Sabouraud medium respectively by streaking on the plate, and then cultivate the colonies. Culture conditions: Agar medium $35^{\circ} \mathrm{C}$ for 48 hours, Sabouraud medium $26^{\circ} \mathrm{C}$ for 72 hours.

\subsection{The situation of patients undergoing bronchoscopy during the sampling period in the bronchoscope room:}




\begin{tabular}{|c|c|c|c|}
\hline \multicolumn{4}{|c|}{ Patient status table for bronchoscopy } \\
\hline $\begin{array}{l}\text { Sampling } \\
\text { days }\end{array}$ & Item & $\begin{array}{l}\text { Sampling in the unpurified } \\
\text { group }\end{array}$ & $\begin{array}{l}\text { Sampling in the clean } \\
\text { group }\end{array}$ \\
\hline \multirow[t]{2}{*}{ Day 1} & $\begin{array}{l}\text { Number of } \\
\text { patients }\end{array}$ & 6 & 1 \\
\hline & Sampling time & $2 \mathrm{~h}$ & $2 \mathrm{~h}$ \\
\hline \multirow[t]{2}{*}{ Day 2} & $\begin{array}{l}\text { Number of } \\
\text { patients }\end{array}$ & 2 & 2 \\
\hline & Sampling time & $3 \mathrm{~h}$ & $3 \mathrm{~h}$ \\
\hline \multirow[t]{2}{*}{ Day 3} & $\begin{array}{l}\text { Number of } \\
\text { patients }\end{array}$ & 5 & 1 \\
\hline & Sampling time & $2 \mathrm{~h}$ & $2 \mathrm{~h}$ \\
\hline \multirow[t]{2}{*}{ Day 4} & $\begin{array}{l}\text { Number of } \\
\text { patients }\end{array}$ & 1 & 1 \\
\hline & Sampling time & $3 \mathrm{~h}$ & $3 \mathrm{~h}$ \\
\hline \multirow[t]{2}{*}{ Day 5} & $\begin{array}{l}\text { Number of } \\
\text { patients }\end{array}$ & 14 & 3 \\
\hline & Sampling time & $3.5 \mathrm{~h}$ & $3.5 \mathrm{~h}$ \\
\hline \multirow[t]{2}{*}{ Day 6} & $\begin{array}{l}\text { Number of } \\
\text { patients }\end{array}$ & 5 & 1 \\
\hline & Sampling time & $3.5 \mathrm{~h}$ & $3.5 \mathrm{~h}$ \\
\hline \multirow[t]{2}{*}{ Day 7} & $\begin{array}{l}\text { Number of } \\
\text { patients }\end{array}$ & 3 & 5 \\
\hline & Sampling time & 2h18min & $2 \mathrm{~h} 18 \mathrm{~min}$ \\
\hline \multirow[t]{2}{*}{ Day 8} & $\begin{array}{l}\text { Number of } \\
\text { patients }\end{array}$ & 5 & 2 \\
\hline & Sampling time & $2 \mathrm{~h}$ & $2 \mathrm{~h}$ \\
\hline \multirow[t]{2}{*}{ Day 9} & $\begin{array}{l}\text { Number of } \\
\text { patients }\end{array}$ & 7 & 1 \\
\hline & Sampling time & $2 \mathrm{~h} 5 \mathrm{~min}$ & $2 \mathrm{~h} 5 \mathrm{~min}$ \\
\hline \multirow[t]{2}{*}{ Day 10} & $\begin{array}{l}\text { Number of } \\
\text { patients }\end{array}$ & 3 & 0 \\
\hline & Sampling time & $1 \mathrm{~h}$ & $1 \mathrm{~h}$ \\
\hline Day 11 & $\begin{array}{l}\text { Number of } \\
\text { patients }\end{array}$ & 7 & 4 \\
\hline
\end{tabular}




\begin{tabular}{|c|c|c|c|}
\hline \multicolumn{4}{|c|}{ Patient status table for bronchoscopy } \\
\hline & Sampling time & 2h40min & 2h40min \\
\hline \multirow[t]{2}{*}{ Day 12} & $\begin{array}{l}\text { Number of } \\
\text { patients }\end{array}$ & 5 & 2 \\
\hline & Sampling time & $2 \mathrm{~h}$ & $2 \mathrm{~h}$ \\
\hline \multirow[t]{2}{*}{ Day 13} & $\begin{array}{l}\text { Number of } \\
\text { patients }\end{array}$ & 13 & 0 \\
\hline & Sampling time & $2 \mathrm{~h} 30 \mathrm{~min}$ & $2 \mathrm{~h} 30 \mathrm{~min}$ \\
\hline \multirow[t]{2}{*}{ Day 14} & $\begin{array}{l}\text { Number of } \\
\text { patients }\end{array}$ & 4 & 1 \\
\hline & Sampling time & 3h10min & $3 \mathrm{~h} 10 \mathrm{~min}$ \\
\hline \multirow[t]{2}{*}{ Day 15} & $\begin{array}{l}\text { Number of } \\
\text { patients }\end{array}$ & 2 & 0 \\
\hline & Sampling time & 1h30min & 1h30min \\
\hline \multirow[t]{2}{*}{ Day 16} & $\begin{array}{l}\text { Number of } \\
\text { patients }\end{array}$ & 6 & 1 \\
\hline & Sampling time & $3 \mathrm{~h}$ & $3 \mathrm{~h}$ \\
\hline \multirow[t]{2}{*}{ Total } & $\begin{array}{l}\text { Number of } \\
\text { patients }\end{array}$ & 88 & 35 \\
\hline & Sampling time & $39 \mathrm{~h} 13 \mathrm{~min}$ & 39h13min \\
\hline
\end{tabular}

\section{Results}

\subsection{Next-generation sequencing (mNGS) detection:}

Purification efficiency $=$ (copy number of unpurified group-copy number of purified group)/copy number of unpurified group $=88.0 \%$.

The results are as follows:

The purification efficiency of individual microorganisms are respectively: Gardnerella vaginalis $62.5 \%$, Staphylococcus capitis 100\%, Micrococcus luteus 100\%, Actinomyces neresii 100\%, Pantoea agglomerans $100 \%$, and actinomycetes purulent. $100 \%$ of bacteria.

The researchers used SPSS statistics 26 to perform non-parametric tests, and the statistical results are as follows: At the level of $a=0.05, P<0.05$, the researcher can think that there is a statistical difference in the copy number of next-generation sequencing (mNGS) of different microorganisms between the unpurified group and the purified group. 


\subsection{Bacteria and fungi culture and identification results}

\section{(1) Colony count result}

The comparison of the total number of colonies between the purified group and the unpurified group is as follows:

Purification efficiency $=$ (the number of colonies in the unpurified group-the number of colonies in the purified group) / the number of colonies in the unpurified group $=87.5 \%$

\section{(2) Strain identification results}

The researchers identified the dominant colonies in the culture medium. The results are as follows:

Among them, Aspergillus flavus is a special case, the discussion part will be analyzed separately. The purification efficiency of the remaining 5 microorganisms are: Aspergillus fumigatus: $87.5 \%$, Aspergillus niger: $100 \%$, Klebsiella pneumoniae: $100 \%$, Micrococcus luteus: $100 \%$, Bacillus subtilis: $50 \%$.

The researchers performed non-parametric tests on the remaining 5 microorganisms using SPSS statistics 26. The statistical results are as follows: At the level of $a=0.05, P<0.05$, the researcher can think that there is a statistical difference in the number of colonies of different types of microorganisms between the unpurified group and the purified group.

\subsection{Case investigation}

The researchers retrieved the information of patients who underwent bronchoscopy during the sampling period and recorded their clinical microbiological test results such as sputum culture, blood culture, respiratory pathogen antibody detection, alveolar lavage fluid culture, and second-generation sequencing of alveolar lavage fluid ( $\mathrm{mNGS}$ ) and so on. The researchers found that during the sampling period of the unpurified group, the corresponding microorganisms that were consistent with the experimental results were found as follows: Klebsiella pneumoniae, Actinomyces endostei, Staphylococcus capitis, Gardnerella vaginalis, Pseudomonas aeruginosa Spp., Stenotrophomonas maltophilia, and Fusarium. During the sampling period of the purified group, the corresponding bacteria or fungi that were consistent with the experimental results were found as follows: Aspergillus flavus. 


\section{Related microbial test results of this experiment}

Sampling Sampling in the unpurified group days

Sampling in the decontamination group
Day 3
Klebsiella pneumoniae

Day 4

Micrococcus luteus

Day 5 Pseudomonas aeruginosa, Actinomycetes, Gardnerella vaginalis, Fusarium

\begin{tabular}{|lll} 
Day 6 & Klebsiella pneumoniae & Pseudomonas aeruginosa \\
Day 7 & Staphylococcus capitis, Klebsiella pneumoniae & $\begin{array}{l}\text { Actinomycetes, Aspergillus flavus, } \\
\text { Pseudomonas aeruginosa }\end{array}$
\end{tabular}

Day 8 Pseudomonas aeruginosa, Stenotrophomonas maltophilia

Day 9 Pseudomonas aeruginosa, Klebsiella pneumoniae

Day 11 Klebsiella pneumoniae

Day 13 Stenotrophomonas maltophilia

Day $14 \quad$ Pseudomonas aeruginosa

Day 15 Klebsiella pneumoniae

Day 16 Pseudomonas aeruginosa

\section{Conclusion}

1. In a normal diagnosis and treatment environment, the new air purifier has a cleaning effect of more than $85 \%$ on aerosol microorganisms in the bronchoscope room; 2 . Various microorganisms involved in the experiment are spread through aerosols.

\section{Discussion}

Experiments have confirmed that after purification by the new type of purifier, the total number of copies and colonies in the bronchoscope room has been greatly reduced, and the total purification efficiency is $87.5 \%-88 \%$. Moreover, individual strains identified by mNGS and microbial culture also have different degrees of declining, with a purification efficiency of $50 \%-100 \%$, and most of the strains have a purification efficiency of $100 \%$. It can be seen that in the dynamic environment of normal diagnosis and treatment in the bronchoscope room, the new type of purifier has a good purification efficiency for indoor 
microbial aerosols. The long-term, large-volume sampling method used in this experiment conforms to the regulations of statistics.

After purification, the total amounts and types of most microorganisms are greatly reduced. However, there is a special case: Aspergillus flavus. The researchers conducted a case search and found that the only patient whose clinical microbiological examination results were positive for Aspergillus flavus entered the bronchoscopy room during the sampling period of the purified group and was examined by bronchoscopy. Therefore, the aerosols of Aspergillus flavus are produced in the purificed group and collected by the sampling membranes. The sampling membranes sent for microbial culture and strain identification is the $2 / \mathrm{B}$ one, which is $2.5-3.5 \mathrm{~m}$ away from the patient and is the closest. Due to the application of the purifier's steady-state replacement flow, the indoor air flow is slow, and its normal airflow cannot be detected by the human body. After the aerosol produced by the patient, it has not been eliminated by the purifier immediately, and it has been collected by the sampling membrane. The reason for the unexistence of Aspergillus flavus in the mNGS results is that the sampling positions of the membranes submitted to mNGS are far away from the patients, and the aerosols produced by the patients are not collected by the sampling membranes in time. The above is the reason that the number of colonies of Aspergillus flavus in the purified group is more than that in the unpurified group. This situation is inevitable in the dynamic environment of the current experiment. Even so, the overall microbial removal rate of the experiment was not affected. This experiment uses two methods for microbial detection, and the experimental results are surprisingly similar. This can prove that the new type of purifier has a relatively stable purification efficiency for indoor microbial aerosols in a dynamic diagnosis and treatment environment, which is $87.5 \%-88 \%$.

The purification time of the experiment was set to $40 \mathrm{~min}$. The new air purifier can have a relatively obvious particle materials purification effect when it is opened for about 10 minutes, which has been confirmed in the airtight experimental chamber. However, in the normal diagnosis and treatment environment of the bronchoscope room, a more stable particle materials purification effect can be achieved 40 minutes after the purifier is turned on. Therefore, the purification time set in this experiment is 40 minutes. Compared with traditional disinfection methods, the new type of purifier can be used in a medical environment at any time. The new type of purifier is equipped with an upwind side and a downwind side, which can protect the safety of medical staff and patients to the greatest extent, and can also push the indoor particulate matter down to the greatest extent, keeping it away from the mouth and nose of medical staff and patients, and reduce the chance of infection in hospital.

The current SARS-CoV-2 pandemic, many countries are currently experiencing an epidemic of the novel coronavirus, causing serious casualties and economic losses. Many outbreaks of epidemics are closely related to the indoor environment. Previous studies have agreed that the infection of the endoscopy room is related to the cross-infection of endoscopic equipment ${ }^{[37]}$. But based on the current sampling results of microbial aerosols, researchers have found that the infection of the endoscopy room is also related to microbial aerosols. So further research are to be done. The new type of air purifier involved in this experiment has a removal efficiency of approximately $85 \%$ for microorganisms under the dynamic 
conditions of the hospital's normal diagnosis and treatment. Such removal efficiency may have a positive effect on the control of the epidemic.

\section{Declarations}

\section{Ethics approval and consent to participate( Human Ethics, Animal Ethics or Plant Ethics)}

Not applicable.

\section{Consent for publication}

The Author confirms:

that the work described has not been published before;

that it is not under consideration for publication elsewhere;

that its publication has been approved by all co-authors, if any;

That its publication has been approved by the responsible authorities at the institution where the work is carried out.

\section{Availability of data and material}

Not applicable.

\section{Competing interests}

The authors have no conflicts of interest or financial relationships impacting this manuscript.

\section{Fundings}

All funding for this study was supported by the Institute of Respiratory Diseases, the Second Hospital of Hebei Medical University.

\section{Authors' contributions}

Lijuan Wu: Methodology, Software, Writing, Data Curation, Editing, 
Xixin Yan: Supervision

The manuscript was drafted by Lijuan Wu and supervised by Xixin Yan, who both critically reviewed and contributed to the final version, which was approved by both.

\section{Contributor's Emails}

Lijuan Wu: xiaochengbuyu@163.com

Xixin Yan: xi_xin_yan@126.com

\section{Acknowledgments}

At the point of finishing this paper, l'd like to express my sincere thanks to all those who have lent me hands in the course of my writing this paper. First of all, l'd like to take this opportunity to show my sincere gratitude to my supervisor, Mr. Yan, who has given me so much useful advices on my writing, and has tried his best to improve my paper. Secondly, l'd like to thank those leaders, teachers and working staff especially those in The second hospital of Hebei Medical University. With their help, my study and this paper finished smoothly.

\section{References}

1. Liu L, Li Y, Nielsen PV, Wei J, Jensen RL. Short-range airborne transmission of expiratory droplets between two people. Indoor Air. 2017 Mar;27(2):452-62.

2. Landry SA, Barr JJ, MacDonald MI, Subedi D, Mansfield D, Hamilton GS, Edwards BA, Joosten SA. Viable virus aerosol propagation by positive airway pressure circuit leak and mitigation with a ventilated patient hood. Eur Respir J. 2021 Jun;24(6):2003666. 57(.

3. Qian H, Li Y. Removal of exhaled particles by ventilation and deposition in a multibed airborne infection isolation room. Indoor Air. 2010 Aug;20(4):284-97.

4. Pankhurst CL, Coulter WA. Do contaminated dental unit waterlines pose a risk of infection? J Dent. 2007 Sep;35(9):712-20.

5. Mirhoseini SH, Nikaeen M, Khanahmd H, Hatamzadeh M, Hassanzadeh A. Monitoring of airborne bacteria and aerosols in different wards of hospitals - Particle counting usefulness in investigation of airborne bacteria. Ann Agric Environ Med. 2015;22(4):670-3.

6. Maclntyre R, Dwyer D, Seale H, Quanyi W, Yi Z, Yang P, et al. High risk procedures and respiratory infections in hospital health care workers-Quantifying the risk. 2014:e379.

7. Mariani A, Capurso G, Marasco G, Bertani H, Crinò SF, Magarotto A, Tringali A, Pasquale L, Arcidiacono PG, Zagari RM. Factors associated with risk of COVID-19 contagion for endoscopy 
healthcare workers: A survey from the Italian society of digestive endoscopy. Dig Liver Dis. 2021 May;53(5):534-9.

8. Jarvis MC. Aerosol Transmission of SARweiS-CoV-2: Physical Principles and Implications. Front Public Health. 2020 Nov 23;8:590041.

9. Tellier R, Li Y, Cowling BJ, Tang JW. Recognition of aerosol transmission of infectious agents: a commentary. BMC Infect Dis. 2019 Jan 31;19(1):101.

10. Michele TM, Cronin WA, Graham NM, Dwyer DM, Pope DS, Harrington S, Chaisson RE, Bishai WR. Transmission of Mycobacterium tuberculosis by a fiberoptic bronchoscope. Identification by DNA fingerprinting. JAMA. 1997 Oct 1;278(13):1093-5.

11. Colenutt C, Gonzales JL, Paton DJ, Gloster J, Nelson N, Sanders C. Aerosol transmission of foot-andmouth disease virus Asia-1 under experimental conditions. Vet Microbiol. 2016 Jun 30;189:39-45.

12. Judson SD, Munster VJ. Nosocomial Transmission of Emerging Viruses via Aerosol-Generating Medical Procedures. Viruses. 2019 Oct 12;11(10):940.

13. Murr A, Lenze NR, Brown WC, Gelpi MW, Ebert CS Jr, Senior BA, Thorp BD, Zanation AM, Kimple AJ. Quantification of Aerosol Particle Concentrations During Endoscopic Sinonasal Surgery in the Operating Room. Am J Rhinol Allergy. 2021 Jul;35(4):426-31.

14. Haw A, McPeck M, Cuccia AD, Smaldone GC. Face Mask Leak Determines Aerosol Delivery in Noninvasive Ventilation. Respir Care. 2021 Jan;66(1):95-103.

15. Agarwal A, Fernando SM, Honarmand K, Bakaa L, Brar S, Granton D, Chaudhuri D, Chetan D, Hu M, Basmaji J, Muttalib F, Rochwerg B, Adhikari NKJ, Lamontagne F, Murthy S, Hui DS, Gomersall CD, Mubareka S, Diaz J, Burns KE, Couban R, Vandvik PO. Risk of dispersion or aerosol generation and infection transmission with nasopharyngeal and oropharyngeal swabs for detection of COVID-19: a systematic review. BMJ Open. 2021 Mar 17;11(3):e040616.

16. Mariani A, Capurso G, Marasco G, Bertani H, Crinò SF, Magarotto A, Tringali A, Pasquale L, Arcidiacono PG, Zagari RM. Factors associated with risk of COVID-19 contagion for endoscopy healthcare workers: A survey from the Italian society of digestive endoscopy. Dig Liver Dis. 2021 May;53(5):534-9.

17. Zhao C, Viana A Jr, Wang Y, Wei HQ, Yan AH, Capasso R. Otolaryngology during COVID-19: Preventive care and precautionary measures. Am J Otolaryngol. 2020 Jul-Aug;41(4):102508.

18. du Toit T, Buchel OC, Smit SJ. Helicobacter pylori as an occupational hazard in the endoscopy room. S Afr J Surg. 2015 Dec;53(3 and 4):23-5.

19. Lai THT, Tang EWH, Chau SKY, Fung KSC, Li KKW. Stepping up infection control measures in ophthalmology during the novel coronavirus outbreak: an experience from Hong Kong. Graefes Arch Clin Exp Ophthalmol. 2020 May;258(5):1049-55.

20. Jungo S, Moreau N, Mazevet ME, Ejeil AL, Biosse Duplan M, Salmon B, Smail-Faugeron V. Prevalence and risk indicators of first-wave COVID-19 among oral health-care workers: A French epidemiological survey. PLoS One. 2021 Feb;11(2):e0246586. 16(. 
21. Luongo JC, Barberán A, Hacker-Cary R, Morgan EE, Miller SL, Fierer N. Microbial analyses of airborne dust collected from dormitory rooms predict the sex of occupants. Indoor Air. 2017 Mar;27(2):33844.

22. Maestre JP, Jennings W, Wylie D, Horner SD, Siegel J, Kinney KA. Filter forensics: microbiota recovery from residential HVAC filters. Microbiome. 2018 Jan;30(1):22. 6(.

23. Jia-Ying L, Zhao C, Jia-Jun G, Zi-Jun G, Xiao L, Bao-Qing S. Efficacy of air purifier therapy in allergic rhiniti. Asian Pac J Allergy Immunol. 2018 Dec;36(4):217-21.

24. Park KH, Sim DW, Lee SC, Moon S, Choe E, Shin H, Kim SR, Lee JH, Park HH, Huh D, Park JW. Effects of Air Purifiers on Patients with Allergic Rhinitis: a Multicenter, Randomized, Double-Blind, and Placebo-Controlled Study. Yonsei Med J. 2020 Aug;61(8):689-97.

25. Park HK, Cheng KC, Tetteh AO, Hildemann LM, Nadeau KC. Effectiveness of air purifier on health outcomes and indoor particles in homes of children with allergic diseases in Fresno, California: $A$ pilot study. J Asthma. 2017 May;54(4):341-6.

26. Chen QY, Li L, Zhang L, Mo JH, Yang ZF, Wei XL, Li YY, Xia JY, Bai XB, Xie PF. Efficacy of indoor air purification in treating Artemisia (mugwort) pollen allergic rhinitis: study protocol for a randomised controlled trial. BMC Public Health. 2018 Jul 6;18(1):841.

27. Cheek E, Guercio V, Shrubsole C, Dimitroulopoulou S. Portable air purification: Review of impacts on indoor air quality and health. Sci Total Environ. 2021 Apr;20:766:142585.

28. Hashimoto K, Kawakami Y. Effectiveness of Airborne Fungi Removal by using a HEPA Air Purifier Fan in Houses. Biocontrol Sci. 2018;23(4):215-21.

29. Lee JH, Kim JY, Cho BB, Anusha JR, Sim JY, Raj CJ, Yu KH. Assessment of air purifier on efficient removal of airborne bacteria, Staphylococcus epidermidis, using single-chamber method. Environ Monit Assess. 2019 Nov;6(12):720. 191(.

30. Echavarria M, Kolavic SA, Cersovsky S, Mitchell F, Sanchez JL, Polyak C, Innis BL, Binn LN. Detection of adenoviruses (AdV) in culture-negative environmental samples by PCR during an AdV-associated respiratory disease outbreak. J Clin Microbiol. 2000 Aug;38(8):2982-4.

31. Dee S, Batista L, Deen J, Pijoan C. Evaluation of an air-filtration system for preventing aerosol transmission of Porcine reproductive and respiratory syndrome virus. Can J Vet Res. 2005 Oct;69(4):293-8.

32. Razzini K, Castrica M, Menchetti L, Maggi L, Negroni L, Orfeo NV, Pizzoccheri A, Stocco M, Muttini S, Balzaretti CM. SARS-CoV-2 RNA detection in the air and on surfaces in the COVID-19 ward of a hospital in Milan, Italy. Sci Total Environ. 2020 Nov;10:742:140540.

33. Cheng VC, Wong SC, Chan VW, So SY, Chen JH, Yip CC, Chan KH, Chu H, Chung TW, Sridhar S, To KK, Chan JF, Hung IF, Ho PL, Yuen KY. Air and environmental sampling for SARS-CoV-2 around hospitalized patients with coronavirus disease 2019 (COVID-19). Infect Control Hosp Epidemiol. 2020 Nov;41(11):1258-65.

34. Liu Y, Ning Z, Chen Y, Guo M, Liu Y, Gali NK, Sun L, Duan Y, Cai J, Westerdahl D, Liu X, Xu K, Ho KF, Kan H, Fu Q, Lan K. Aerodynamic analysis of SARS-CoV-2 in two Wuhan hospitals. Nature. 2020 
Jun;582(7813):557-60.

35. Kenarkoohi A, Noorimotlagh Z, Falahi S, Amarloei A, Mirzaee SA, Pakzad I, Bastani E. Hospital indoor air quality monitoring for the detection of SARS-CoV-2 (COVID-19) virus. Sci Total Environ. 2020 Dec;15:748:141324.

36. Chia PY, Coleman KK, Tan YK, Ong SWX, Gum M, Lau SK, Lim XF, Lim AS, Sutjipto S, Lee PH, Son TT, Young BE, Milton DK, Gray GC, Schuster S, Barkham T, De PP, Vasoo S, Chan M, Ang BSP, Tan BH, Leo YS, Ng OT, Wong MSY, Marimuthu K. Singapore 2019 Novel Coronavirus Outbreak Research Team. Detection of air and surface contamination by SARS-CoV-2 in hospital rooms of infected patients. Nat Commun. 2020 May;29(1):2800. 11(.

37. Kong X, Zhu X, Zhang Y, Wu J. The application of plan, do, check, act (PDCA) quality management in reducing nosocomial infections in endoscopy rooms: It does work. Int J Clin Pract. 2021 Aug;75(8):e14351.

\section{Supplementary}

Due to technical limitations, (1) Colony count result table is only available as a download in the Supplemental Files section.

\section{Figures}

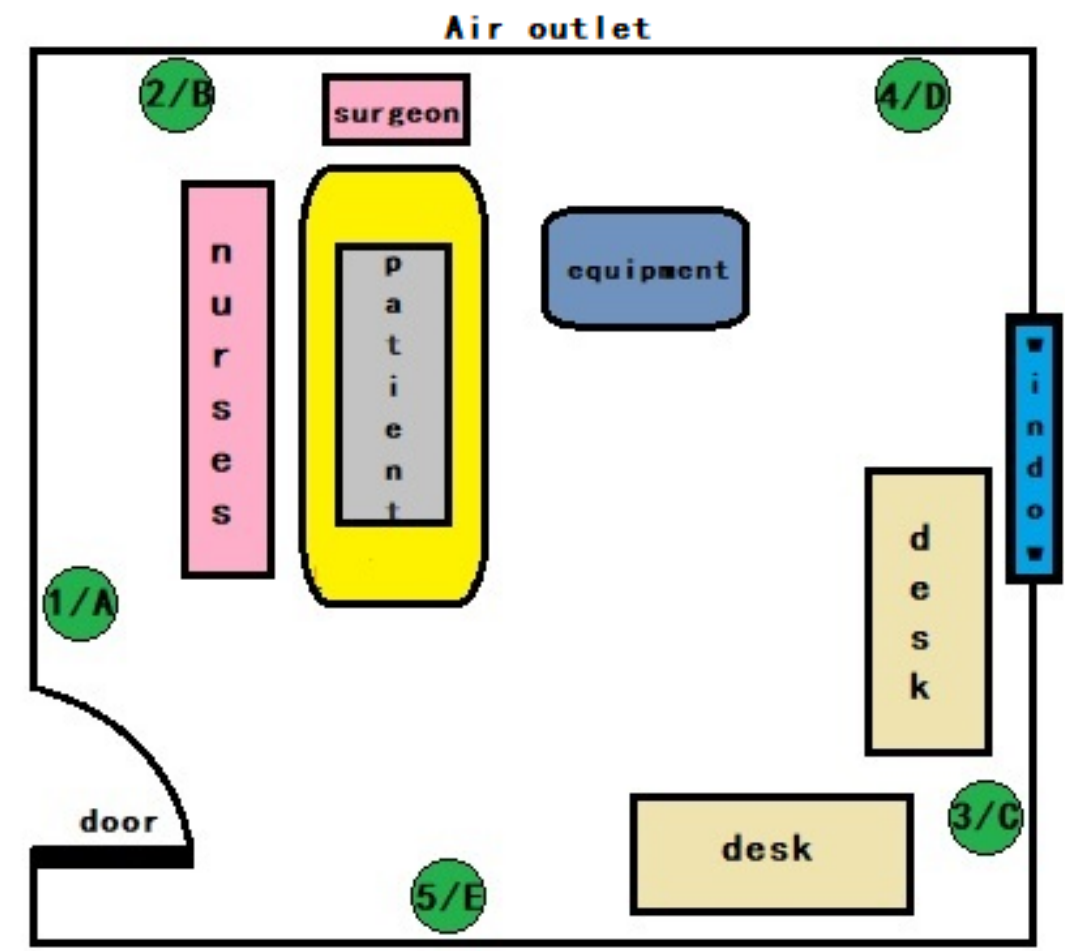

Air inlet

Figure 1 


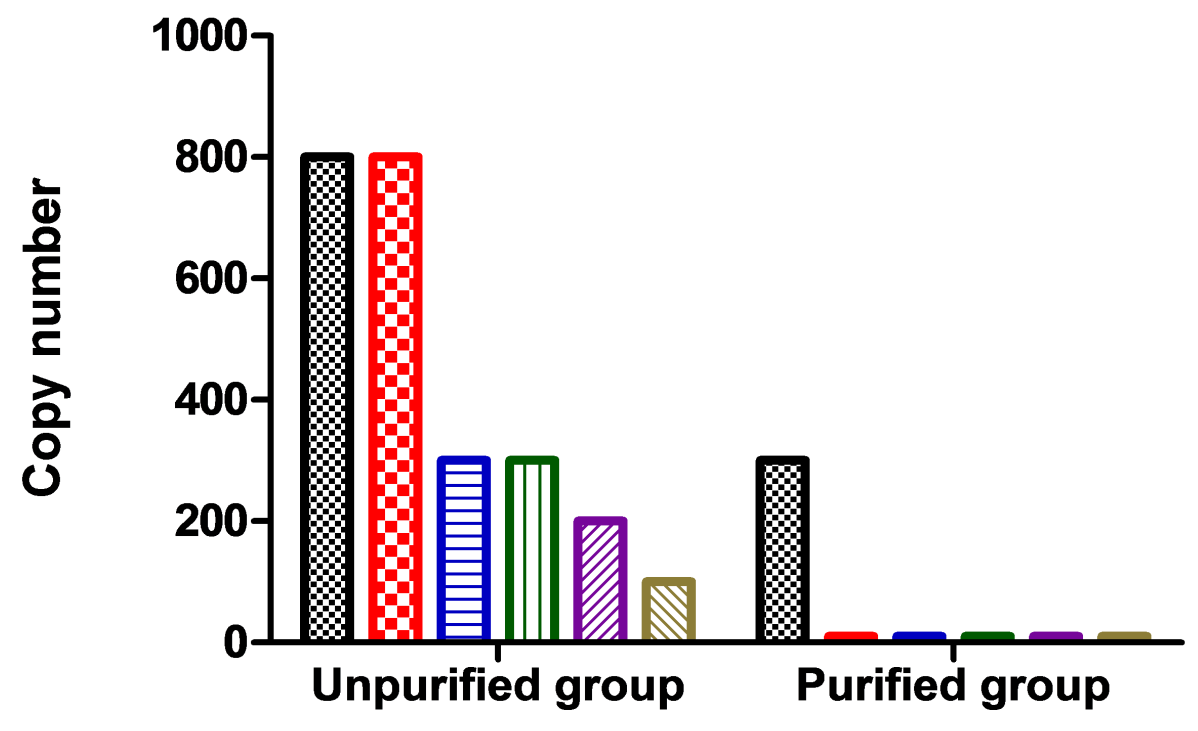

\% Gardnerella vaginalis

Etaphylococcus capitis

בMicrococcus luteus

III Actinomyces neseri

IIS Pantoea agglomerans

Actinomyces pyogenes

Figure 2

Results of NGS test 


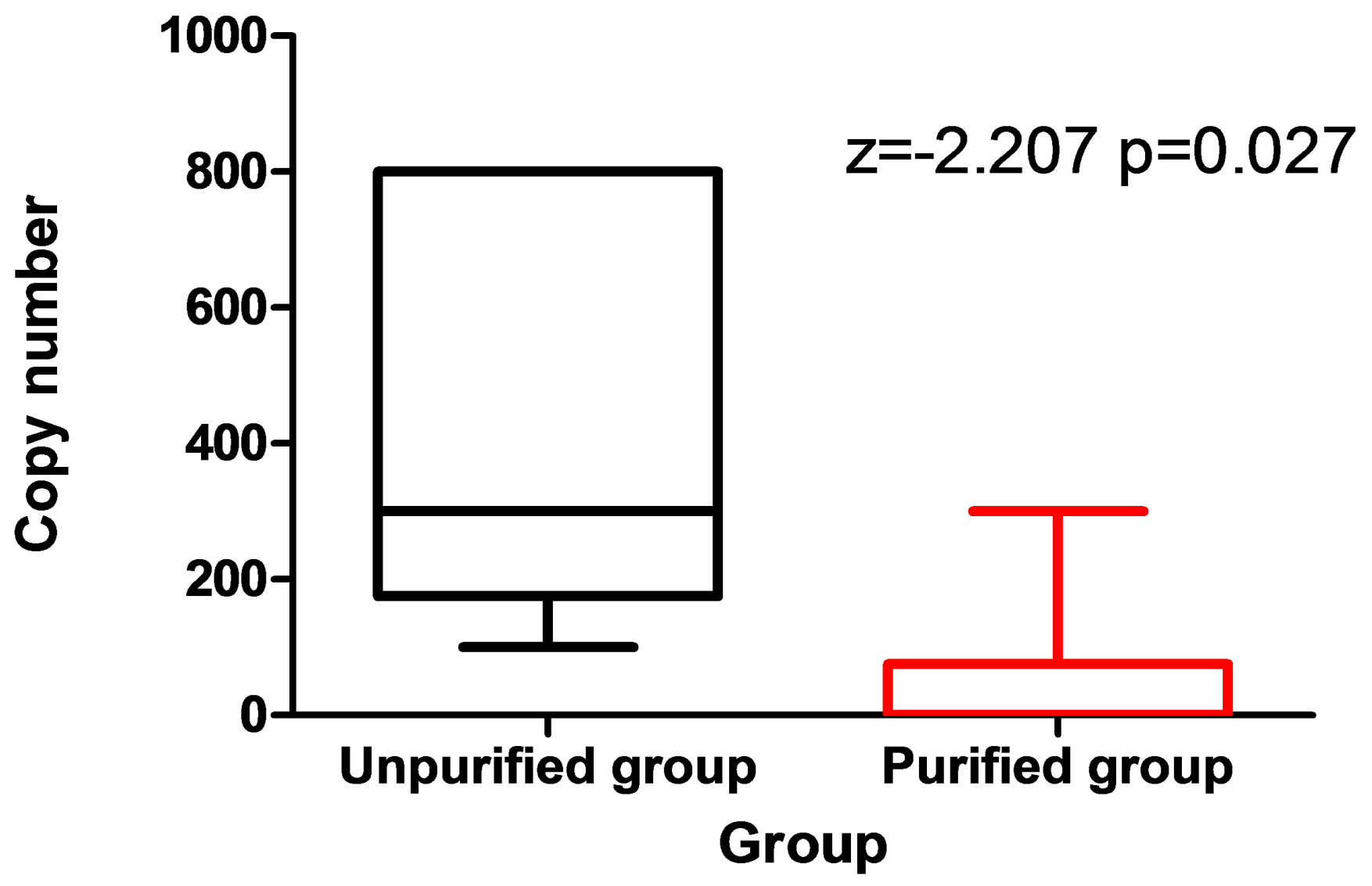

Figure 3

Statistics results of NGS test

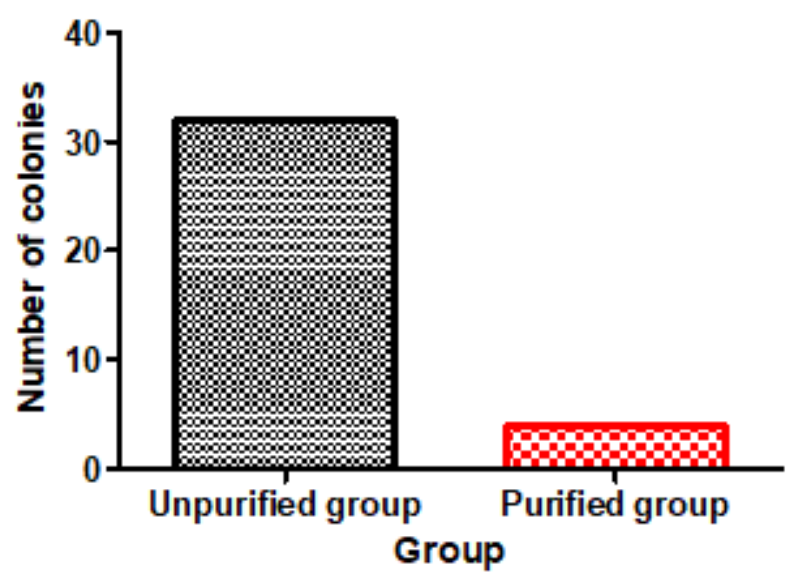

Figure 4

Results of total number of colonies in the microbial culture test 


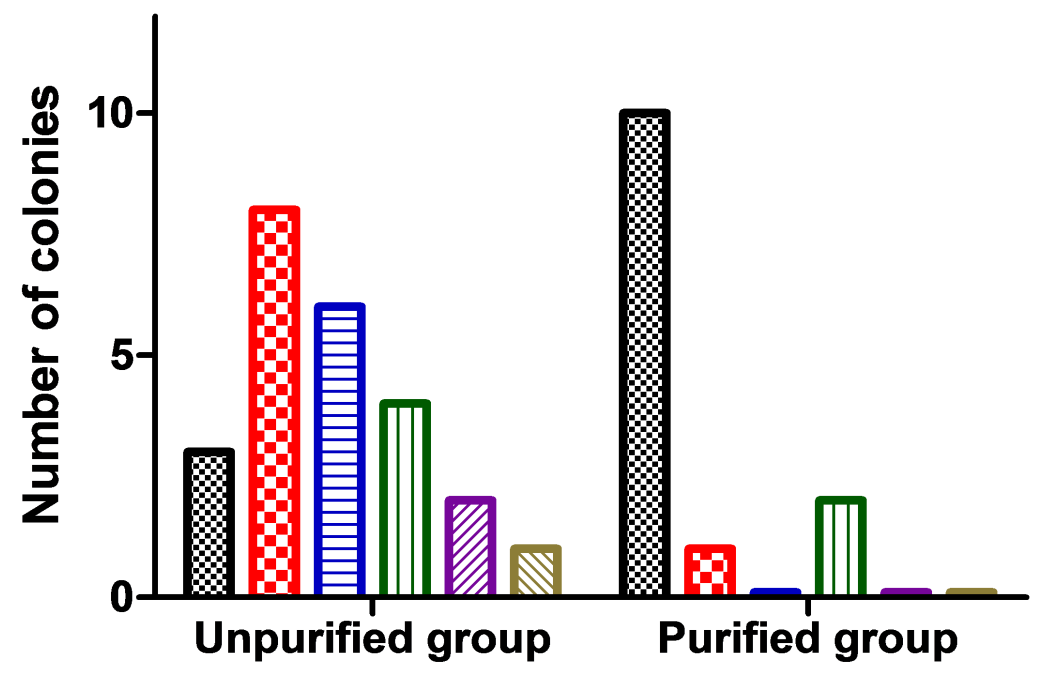

\# Aspergillus flavus

Aspergillus fumigatus

Ð Micrococcus luteus

미 Bacillus subtilis

IIs Aspergillus niger

Nev Klebsiella pneumoniae

Figure 5

Results of microbial culture and identification test

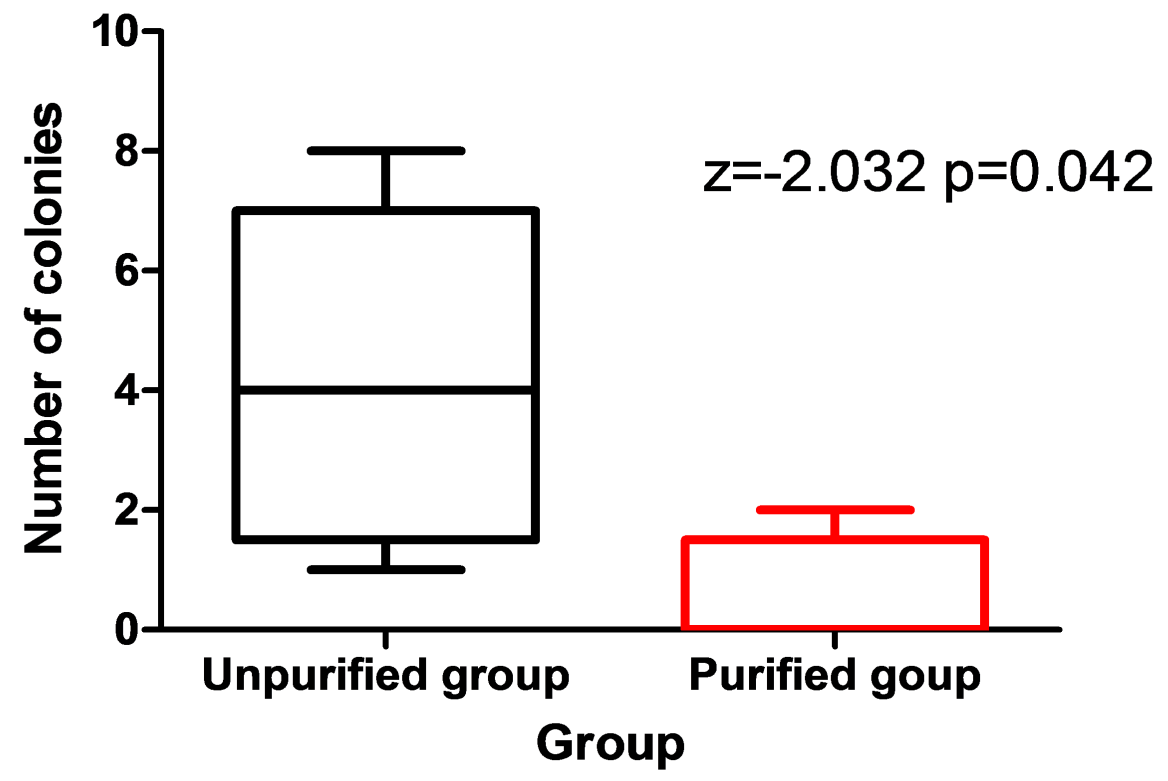

Figure 6

Statistic results of microbial culture and identification test

Supplementary Files 
This is a list of supplementary files associated with this preprint. Click to download.

- Graphicalabstract.png

- 1Colonycountresult.png 